\title{
LXX. On a new mode of artificial congelation
}

\section{John Leslie F.R.S.E.}

To cite this article: John Leslie F.R.S.E. (1818) LXX. On a new mode of artificial congelation, Philosophical Magazine Series 1, 51:242, 411-421, DOI: 10.1080/14786441808637578

To link to this article: http://dx.doi.org/10.1080/14786441808637578

曲 Published online: 27 Jul 2009.

Submit your article to this journal

Џ Article views: 2

Q View related articles $₫$ 


\section{Description of the Plate No.7, [see Pl. IV.]}

Fig. 1. Presents the end of the radicle just where it is enlarged from the side root. $a a$ are the first forming of the balls, which are certainly the hearts of the seeds; and $b b$ the larger balls where they take in the little shoot. Leuwenhoek and Mr. H. Baker saw this shoot as well as l.

2. The alburnum vessels branching up from the root $c c$, till they reach the buds passing through the alburnum vessel.

3 . The bud of the cucumber cut longitudinally, slrowing its interior, $d d$ its female fowers, with $e e$ its seed-vessel and seeds, when the hearts of the seeds begin to fix themselves on the seeds $f f$; and run up the fower-stem $g g$.

4. The seed-vessel cut horizontally, showing the peculiar hair belonging to the first fixing of the seeds, when they are taking in their bearts to the seeds, as at $h h$.

5. The cutting longitudinally when the seeds receive the juices of the atmosphere from the peculiar hair $i$.

f. When the same hair is continued and the matter is received from the roots by the peculiar figure $k k$.

7 . The horizontal cutting of the stem of the cucumber, howing the apertures which admit the powder all the way up the root within the pith.

$\Upsilon, 9,10$. The three hairs: the first begins in the very early bud.

11. The sort of excrescence that admits the powder, and throws it into the seed at $l l$.

LXY. On a new Mcte of Artificial Congelation. By ЈоHN L.ESLIE, F.R.S. E. Professor of Mathematics in the University of Edinburgh".

W

$\mathrm{E}$ have now to relate a discovery which will enable human will to command the refrigerating powers of nature ; and, by the help of an adequate machinery, to create cold and produce ice, on a large scale, at all seasons, and in the hottest climates of the globe. But, to explain this interesting subject with greater elcamess and accuracy, it is requisite to trace the successive advances which conducted to the result. Where a conclusion appears simple, the careless observer is apt to suppose it easily at-

- Fron Supplement to the fourth and fifth editions of the Encyclo-

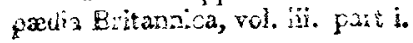

tained; 
tained; yel, though sound philosophy tends always to simplification, the rare quality of simplicity is scarcely ever the flash of intuition, but the slow fruit of close and patient investigation.

In pursuing the researches with his hygrometer, Professor Leslie was early induced to inquire into the condition of the higher atmosphere, and its relations to humidity. He thus detected a fact of great importance in meteorology, and pointing at various ulterior views.

\section{Investigation of its Rrinciples.}

As rąrefaction enlarges the capacity of air for heat, so it likewise augments the lisposition to hold moisture; at the same time, that the removal of the ordinary pressure facilitates the expansion of the liquid matter, and its conversion into a gaseots form. Accordingly, if the hygrometer be suspended within a large receiver, from which a certain portion of air is quickly abstracted, it will sink with rapidity. In summer the additional dryness thus produced amounts to about 50 hygrometric degrees, each time the air has its rarefaction doubled; so that, supposing the operation of exhausting to be performed with expedition, and the residuum reduced to a sixty-fourth part, the hygrometer would mark a descent of $300^{\circ}$. But this effect is only momentary; for the thin air very soon becomes charged with moisture, and, consequently, ceases to act on the wet ball of the hygrometer. The cold, however, excited on the surface of that ball, by such intense evaporation, will have previously frozen the conting.

The increased power of aqueous solution which air acquires as it grows thinner, being ascertained and carefully investigated, the object was to combine the action of absorbent with the transient dryness produced within a receiver by rarefaction. The sentient ball of the hygrometer being covered with dry salt of tartar, the instrument first indicated increasing dryness, and afterwards, as the rarefaction proceeded, it changed its course, and marked humidity. The same variation of effect nearly was observed, when the hygrometer had been wetted as ustal with pure water, and a broad saucer containing the mild vegetable alkaii was placed on the plate of the air-pump. It was thus proved, that the action of this imperfect absorbent is soon overpowered by the tendency to vaporization in attenuated air, and that, beyond a certain limit, it surrenders its latent moisture.

Mr. Leslie resulved, therefore, to try the effect of sulphuric acid, whose peculiar energy as an absorbent he had, under other circumstances, already ascertained. But various incidents prerented him, for a considerable time, from resuming his philosophical inquirics. At last he began those projected cxperiments, 
nnd was almost immediately rewarded by the disclosure of a property, the application of which blazed on his fancy. In the month of June 1810, having introduced a surface of sulphuric acid under the receiver of an air-puim, he perceived with pleasure that this substance only superadded its peculiar attraction for moisture, to the ordinary effects resulting from the progress of exhaustion; and, what was still more important, that it continued to support, with undiminished energy, the dryness thus created. The attenuated air was not suffered, as before, to grow charged with humidity; but each portion of that medium, as fast as it became saturated by touching the wet ball of the hygrometer, transported its vapour to the acid, and was thence sent back denuded of the load, aifl fitted again to renew its attack with fresh vigour. By this" perpetual circulation, therefore, between the exhaling and the absorbing surface, the diffuse residuum of air is maintained constantly at the same state of dryness. The sentient ball of the hygrometer, which had been covered with several folds of wetted tissue paper, was observet, at an early stage of the operation, suddenly to lose its biue tint and assume a dull white, while the coloured liquor sprung upwards in the stem, where it continued, for the space of a minute, stationary, and again slowly subsided. The act of congelation had, therefore, at this moment taken place, and the paper remained frozen several minutes, till its congealed moisture was entirely dispersed. Pursuing this decisive intimation, the hygrometer was renoved, aut a watch-glass filled with water substituted in its place. By a few strokes of the punp, the whole was converted into a solid cake of ice, which, being left in the rare medium, continued to evaporate, and, after the interval of perhaps an hour, totally disappeared. A small cup for holding the water was next adopted, and the whole apparatus gradually enlarged.

\section{Efficient Pouer nearly the same at all Temperatures.}

The powers, both of vaporization and of absorption, being greatly augmented in the higher temperatures, the same limit of cold nearly is in all cases attained, by a certain measure of exhaustion. When the air has been rarefied 250 times, the utmost that, under such circumstances, can perhaps be effected, the surface of evaporation is cooled down 120 degrees of Fahrenheit in winter, and would probably sink near 200 in summer. Nay, a far less tenuity of the medium, when combined with the action of sulphuric acid, is capable of producing and supporting a very intense cold. If the air be sarefied only 50 times, a depression of temperature will be produced, amonnting to 80 or even 100 degrees of Fathrenheit's scale. 


\section{Mode of proceeding.}

We are thus enabled, in the hottest weather, to freeze a mass of water, and to keep it frozen, till it gradually wastes away, by a a ontinued but invisible process of evaporation. The only thing required is, that the surface of the acid should approach tolerably near to that of the water, and should have a greater extent ; for otherwise the moisture would exhale more copiously than it could be transferred and absorbed, and, consequently, the dryisess of the rarefied medium would become reduced, ind its evaporating energy essentially impaired. The acid should be poured to the depth perhaps of half an inch in a broad flat dish, which is covered by a receiver of a form nearly hemispherical; the water exposed to congelation may be contained in a shallow cup, about half the width of the dish, and having its rim supported by a narrow porcelain ring upheld above the surface of the acid by three slender feet. It is of consequence that the water should be insulated as much as possible, or should present only a humid surface to the contact of the surrounding medium ; for the dry sides of the cup might receive, from communication with the external air, such accessions of heat, as greatly to diminish, if not to counteract the refrigerating effects of evaporation. This inconvenience, however, is in a great measure obviated, by investing the cup with an outer case at the interval of about half an inch. If both the eup and its case consist of glass, the process of congelation is viewed most completely; yet when they are formed of a bright metal, the effect appears on the whole more striking. But the preferable mode, and that which prevents any waste of the powers of refrigeration, is to expose the water in a pan of porous earthen-ware. If common water be used, it will evolve air bubbles very copiously as the exhaustion proceeds; in a few minutes, and long before the limit of rarefaction has been attained, the icy spiculæ will shoot beautifully throigh the liquid mass, and entwine it with a reticulated contexture. As the process of congelation goes forward, a new discharge of air from the substance of the water takes place, and marks the regular advances of consolidation. But after the water has all become solid ice, which, unless it exceed the depth of an inch, may generally be effected in less than half an hour, the circle of evaporation and subsequent absorption is still maintaincd. A minute film of ice, abstracting from the internal mass a redoubled share of heat, passes, by invisible transitions, successively into the state of water and of stearn, which, dissolving in the thin ambient air, is conveyed to the acid, where it again assumes the liquid form, and, in the act of combination, likewise surrenders its heat. 


\section{Moderate Rarefaction sufficient to maintain the Ice.}

In performing this experiment, the object is generally to seek at first to push the rarefaction as far as the circumstances will admit. But the disposition of the water to fill the receiver with vapour, being only in part subdued by the action of the sulphuric ncid, a limit is soon opposed to the progress of exhaustion, and the included air can seldom be rarefied above a hundred times, or till its elasticity can support no more than a column of mercury about three-tenths of an inch in height. A smaller rarefaction, perhaps from ten times to twenty times, will be found sufficient to support congelation after it has once taken place. The ice then becomes rounded by degrees at the edges, and wastes away insensibly, its surface being incessantly corroded by the play of the ambient air, and the minute exhalations conveyed by an invisible process to the sulphuric acid, which, from its absorbing the vapour, is all the time maintained above the temperature of the apartment. The ice, kept in this way, suffers a very slow consumption; for a lump of it, about a pound in weight and two inches thick, is sometimes not entirely gone in the space of eight or ten days. During the whole progress of its wasting, the ice still commonly retains an uniform transparent consistence; but, in a more advanced stage, it occasionally betrays a sort of honey-combed appearance, owing to the minute cavities formed by globules of air, set loose in the act of freezing, yet entangled in the mass, and which are afterwards enlarged by the erosion of the solvent medium.

But almost every practical object is attained, through far inferiot powers of refrigeration. Water is the most easily frozen, by leaving it, perhaps for the spiace of an hour, to the slow action of air that has been rarefied only in a very moderate degree. This process meets with less impediment, and the ice formed by it appears likewise more compact, when the water has been already purged of the greater part of its combined air, either by distillation or by long continued boiling. The water which has undergone such operation, should be introduced as quickly as possible into a decanter, and filled up close to the stopper, else it will attract air most greedily, and return neasly to its former state in the course of a few hours.

\section{Elegant Mode of Freezing.}

The most elegant and instructive mode of effecting artificial congelation, is to perform the process under the transferrer of an air-pump. A thick but clear glass cup being selected, of about two or three inches in diameter, has its lip's ground flat, and covered occasionally, thaigh nct absolutely shut, with a 
broat circular lid of plate-glass; which is suspended horizontally from a rod passing through a collar of leather. This cup is nearly tilled with fresh distilled water, and supported-by a slender metallie ring, with glass feet, about an inch above the surface of it body of sulphuric acid, perhaps three quarters of an inch in thickness, and occupying the bottom of a deep glass Irason that has a diameter of nearly seven inches. In this state, the receiver being adapted, and the lid pressed down to cover the mouth of the cup, the transferrer is screwed to the air-pump, and the rarefaction, under those circumstances, pushed so fir as to leave only about the hundred and fiftieth part of a residuum; and the cooli being turned to secure that exhaustion, the compound apparatus is then detached from the pump, and removed to some couvenient apartment. As long as the cup is covered, the water will remain quite unaltered; but, on drawing up the rod half an inch or more, to admit the play of the rare medium, a bundle of spi. cular ice will, after the lapse perhaps of five minutes, dart sudvienly through the whole of the liquid mass; and the consolidation will afterwarts descend regularly, thickening the horizontal stratum by insensible gradations, and forming in its progress a beautiful transparent cake. On letting down the cover again, the process of evaporation being now checked or almost entirely stopped, the ice returns slowly into its former liquid condition. In this way, the same portion of water may, even at distant intervals of time, be repeatedly congealed and thawed successively ewenty or thirty times. During the first operations of freezing, sonse air is liberated; but this extrication diminishes at each subsequent act, and the ice, free from the smallest specks, resembles a piece of the purest crystal.

\section{Progress of Congelation.}

This artificial freezing of water in a cup of glass or metal, affords the best opportunity of examining the progress of crystallization. The appearance presented, however, is extremely various. When the frigorific action is most intense, the congelation sweeps at once over the whole surface of the water, obscuring it like a cloud. But, in general, the process alvances more slowly; bundles of spicula, from different points, sometimes from the centre, though commonly from the sides of the cup, stretching out and spreading by degrees with a sort of feathered texture. By this combined operation, the surface of the water soon becomes an uniform sheet of ice. Yet the effect is at times singularly varied; the spicular shoots, advancing in different directione, come to inclose, near the middle of the cup, a rectilineal space, which, by unequal though continued encroachment, is reduced to a triangle; and the mass below, being partly frozen, and 
therefore expanded, the water is gradually squeezed up through the orifice, and forms by congelation a regular pyramid, rising by successive steps; or, if the projecting force be greater, and the hole more contracted, it will dart off like a pillar. The radiating or feathered lines wlich at first mark the frozen surface, are only the edges of very thin plates of ice, implanted at determinate angles, but each parcel composed of parallel planes. This internal formation appears very conspicuous in the congeiled mass which has been removed from a metallic cup, before it is entirely consolidated.-Sea water will freeze with almost equal ease; but it forms an incompact ice like congealed syrup, or what is commonly called water-ice.

When cups of glass or metal are used, the cold excited at the cpen surface of the liquid extends its influence gradually downwarts. But if the water be exposed in a porous ressel, the process of evaporation, then tahing ethect on all silles, proceeds with a nearly regular consolidation turadd the centre of the nass, thickening rather faster at the bottom from its proxinity to the action of the absorbent, and leaving sometimes a reticulated space near the middle of the upper sturface, through which the air, disengaged by the progress of cong clation, makes its escape.

\section{Singular Modificalion of the Process.}

When very feeble powers of refrigeration are employed, a most singular and beautiful appcarance is, in course of time, slowly produced. If a pan of porous earthen-ware, from four to six inches vide, be filled to the utmost with common water till it rise above the lips, and planted above a dish of ten or twelve inches diameter, containing a borly of sulphuric acid, and then a broad round receiver placed over it; on reducing the included air to some limit between the twentieth and the fifth part of its usual density, according to the coldness of the apartment, the liquid mass will, in the space of an hour or two, become entwined with icy shoots, which gradually enlarge and acquire more solidity, but always leave the fabric loose and unfrozen below. The icy crust which covers the rim, now receiving continual accessions from beneath, rises perpendicularly by insensible degrees. From each point on the rough surface of the vessel, filaments of ice, like buadles of spun glass, are protruded, fed by the humidity conveyed through its substance, and forming in their aggregation a fine silvery surface, analogous to that of fibrous gypsum of satim-spar. At the same time, another similar growth, though of less extent, takes place on the under side of the pan, so that contiuuous icy threads might appear vertically to transpierce the warc. The whole of the bottom becomes likewise covered over with clegant icy foliations. Twenty or thirty hours may be reFol. 51 . No.:42, Jitie is

D. quired 
quired to produce those singular effects; but the upper body of jee continues to rise for the space of several days, till it forms a circular wall of near three inches in height, leaving an interior grotto lined with fantastic groups of icicles. In the meanwhile the exfoliations have disappeared from the under side, and the outer incrustation is reduced, by the absorbing process, to a narrow ring. The icy wall now suffers a regular waste from external erosion, and its fibrous structure becomes rounded and less apparent. Of its altitude, however, it loses but little for some time; and even a deposition of congealed films along its coping or upper edge, seems to take place, at a certain stage of the process. This curions effect is owing to a circumstance, which, as it serves to explain some of the grand productions of nature, particularly the Iselergs of the Arctic Circle, merits particular attention. The circular margin of the ice, being nearer the action of the sulphuric acid than its inner cavity, must suffer, by direct evaporation, a grater loss of heat ; and, consequently; each portion of thin air that rises from the low cavity, being chilled in passing over the colder ledge, must deposit a minute corresponding share of its moisture, which instantly attaches itself and incrusts the ring. Whatever inequalities existed at first in the surface of the ice, will hence continually increase.

\section{Artificial Congelation best performed on a large Scale.}

Artificial congelation is always most commodiously performed on a large scale. Since the extreme of tarefaction is not wanted, the air-pump employed in the process admits of being considerably simplified, and rendered vastly more expeditious in its operation. Two or three minutes at most will be sufficient for procuring the degree of exhaustion required, and the combined powers of evaporation and absorption will afterwards gradually produce their capital effect. In general, plates of about a foot in diameter should be preferred, which can be connected at pleasure with the main body of the pump. The dish holding the sulphuric acid is nearly as wide as the flat receiver: and a set of evaporating pans belongs to it, of different sizes, from seven to three inches in diameter, which are severally to be used according to circumstances. The largest pan is employed in the cold season, and the smaller ones may be successively taken as the season becomes sultry. On the whole, it is better not to overstrain the operation, and rather to divide the water under different receivers, if unusual powers of refrigeration should be required. As soon as the air is partly extracted from one receiver, the communication is immediately stopped with the barrel of the pump, and the process of exhaustion is repeated on another. In this way, any number of receivers, it is evident, 
may be connected with the same machine. If we suppose but six of these to be used, the labour of a quarter of an hour will set as many evaporating pans in full action, and may, therefore, in less than an hour afterwaris produce nearly six pounds of solid ice. The waste which the water sustains during this conversion is extremelysmall, seldom indesd amounting to the fiftieth part of the whole. Nor, till after multiplied repetitions, is the action of the sulphuric acid considerably enfeebled by its aqueous absorption. At first that diminution is hardly perceptible, not being the hundredth part when the acid has acquired as much as the tenth of its weight of water. But such influence gains rapidly, and rises with accelerated progression. When the quantity of moisture absorbed amounts to the fourth part by weight of the acid, the power of supporting cold is diminished by a twentieth; and, after the weights of both these come to be equal, the refrigerating energy is reduced to less than the half. Sulphuric acid is hence capable of efficting the congelation of more than twenty times its weight of water, before it has imbibed near an equal bulk of that liquid, or has lost about the eighth part of its refrigerating power. The acid should then be removed, and concentrated anew by slow distillation.

Congelation might be connected with the Steam-Engine.

When the exhaling and absorbing surfaces are rightly disposed and apportioned, the moderate rarefaction, fron twenty to forty times, which is adequate to the freczing of water, may be readily procured by the condensation of steam. In all manufactures where the steam-engine is employed, ice may, therefore, at all times be formed in any quantity, and with very little additional expense. It is only required to bring a narrow pipe from the condeusing vessel, and to direct it along a range of receivers, under each of which the water and the acid are severally placed. These receivers, with which the pine communicates by distinct apertures, may, for the sake of ceconomy, be constructed of cast-iron, and adapted with hinges to the rim of a broad shallow dish of the same metal, but lined with lead to hold the acid.

\section{Congelation of Mercury.}

The combined powers of rarefaction and absorption are capable of generating much greater effects than the mere freezing of water. Such frigorific energy, however, is at all times sufficient for effecting the congelation of mercury. Accordingly, if mercury, contained in a hollow pear-sltaped piece of ice, be suspended by cross threads near a broad surface of sulphuric acid under a receiver; on urging the rarefaction, it will become frozen, and may remain in that solid state for the space of several hours. 
But this very striking experinent is easily performed without ary fureign aid. Having introduced mercury into the large bulb of a thermometer, and attached the tube to the rod of a transferrer, lat this be placed over the wide dish containing sulphuric acid, in the midst of which is planted a very small tumbler nearly filled with water. After the included air has been rarefied abont tofty times, let the bulb be dipped repeatedly into the very cold but unfrozen water, and again drawn up about an inch; in this way, it will become incrusted with successive coats of ice, to the thickness perhaps of the twentieth part of an inch. The water being now removed, the pendent icicle cut away from the bulb, and its surface smoothed by the touch of a warm finger, the transferrer is again replaced, the bulb let down within half an inch of the acid, and the exhaustion pushed to the utmost. When the siphon-gauge has come to stand under the tenth of an inch, the icy crust starts into divided fissures, and the mercury, having gradually descended in the tube till it reach its point of congelation, or 39 degreess below zero, sinks by a sudden contraction almost into the cavity of the bulb; and the apparatus being then removed and the ball broken, the metal ap pears a solid shining mass, that will bear the stroke of a hammer.

\section{Still greater Cold created.}

But a still greater degree of cold may be created, by applying the same process likewise to cool the atmosphere which encircles the apparatus itself. A glass matrass was blown nearly of a hemispherical shape, its bottom quite flat, and about three inches in diameter, and its neck about half an inch wide and cut square over. The whole was covered with a coat of patent lint, which takes up water very copiously, a portion of sulphuric acid was next introduced, forming a layer of perhaps a quarter of an inch thick, and a spirit of wine thermometer, having its bulb also cased with wetted lint, was then inserted within the matrass, a brass ring attached to the tube securing it in the right position. Things being thus arranged, the matrass or flat bottle, with its thermometer, was placed on a slender stool with glass feet, about an inch above the sulphuric acid in the broad bason, and the large receiver luted over it. The air was then partiy extracted, till the gauge came below one inch, In a few minutes the lint was frozen entirely, and looked white. After an intervai of a quarter of an hour, to allow time for the evaporation of that icy coat to cool down the interior apparatus, the pump was again urged, and the exhaustion pushed to about three-tenths of an inch. In a short while, the inclosed thermometer sunk not fewer than 180 degrees, and remained stationary, till the ice had wasted away. 
It is obvious, therefore, that the refrigerating powers could he pushed still further by a judicious combination of the apparatus. It would be easy to show, that the maxinum effect is obtained, when the dimensions of the successive cases rine in a geomentical progression. The action, however, is not doubled for each additional ease, but increased rather more than one-half.

\section{تimpler Mode of Congelation, by dry pounded Whinstone, or parched Outmeal.}

These plans are difficult in the execution; and though they enlarge onr conceptions of the exient of the descending scale of heat, yet they furnish merely speculative results. A very important practical improvement has been lateiy made in the process of artificial congelation. Sulphuric acid is certainly a cheap and most powerful agent of absorption; but the danger in using such a corrosive liquid, especially by unskilful persons, formed always a serious obstacle to its general adoption. Mr. Leslie had early noticed the remarkahle absorbent quality of our mouldering whinstone or porphyritic trap; and in April 1817 lie sabstituted that material, grossly pounded and dried before a kitchen fire, instead of sulphuric acid, and actually froze a body of water with great facility. This earth will attract the fiftieth part of its weight of moisture before its absorbent power is reduced to the one-half, and is hence capable of freezing the sixth part of its weight of water. It may be repeatedly dried, and will, after each operation, act with the same energy as at first.

But an absorbent still more convenient and powerful has since oscurred to Mr. Leslie; -it is merely parched outmeal. With a body of oatmeal of a foot in diameter, and rather more than an inch deep, he froze a pound and a quarter of water, contwined in a hemispherical porous cup. The meal is easily dried and restored again to its action. In a hot climate, the exposure to the sun alone might prove sufficient. $\mathrm{BF}$ the help of this simple material, therefore, ice will be easily and safely produced in any climate, and even at sea.

Other substances could, no doubt, be empioved as absorbents. Fict, except the muriate of lime, or what is called the oil of salt sesiccated, none hold out any prospect of success. Dried common salt will barely effect congelation; and stucco, or the sulphate of lime, deprived of its water of erystallization, which might seem to promise a powerful abserption, has scarcely any eaticacy whatever. 